\title{
MODELLING OF FLUID FLOW AND HEAT DISTRIBUTION IN A SPECIFIC HEAT EXCHANGER
}

\author{
D. Fialová, Z. Jegla*
}

\begin{abstract}
An initial phase in the development of a modelling approach to analysing fluid flow and heat distribution in specific heat transfer equipment is presented. A steam superheater as a typical heat exchanger operated in process and power industries is used to introduce the aspects of modelling of this phenomenon. The particular parts of the superheater where problems can be expected are described in order to propose a suitable calculation method which would be applicable to equipment with complex technological and geometric design. Available modelling techniques and approaches are reviewed and applied to the discussed apparatus with distinguishing multiple-channel design and their advantages and limitations are identified. Based on this analysis, principles of a new modelling method are outlined. The proposed modelling method employs a combination of simplified approaches to $1 D$ investigating the flow distribution and $2 D$ analysis of heat transfer in the cross-flow heat exchanger. Additionally, future development of the intended fast yet accurate-enough method for prediction of fluid flow and heat flux distribution in the specific heat exchanger is suggested.
\end{abstract}

Keywords: flow distribution, heat distribution, simplified method, modelling, heat exchanger

\section{Introduction}

Process and power heat transfer equipment often suffers from various problems as a consequence of uneven thermal loading of its heat transfer surface accompanied by fluid flow maldistribution. In extreme cases, the resulting mechanical stress and deformation can lead to a total failure of the apparatus. However, a thermal-hydraulic design of equipment usually considers non-uniform distribution of heat and fluid flow only very simply (if at all), especially because it is often not possible to use modern 3D computational fluid dynamics (CFD) models due to their extremely long computational times. Although there are a number of simplified calculation methods available (in most cases, these are tailored to specific types of heat transfer equipment), designers' distrust of the results and/or the incorrect use of these methods are not unusual. On the other hand, a wide range of industrial heat exchangers are still so complex and unique that common simplified methods are not capable of handling heat flux distribution together with distribution of process fluids. In spite of being computationally intensive and therefore very time-consuming, the employment of CFD simulation for a detailed design is still profitable.

This paper summarises main theoretical findings from the development of a model which facilitates analysis of heat and fluid flow distribution in specific heat transfer equipment with multiple-level channel systems. Purpose of the developed model is to fill the space between the two approaches mentioned above to describe specific heat transfer equipment - when the usage of available simplified methods is not satisfactory and can lead to inaccurate data, whereas the utilisation of CFD simulations is a real effort and the computational cost is unacceptable. The findings are presented by means of an industrial case, which is a heat exchanger with the distinguishing multiple-channel design used to produce superheated steam.

\footnotetext{
Ing. Dominika Fialová: Institute of Process Engineering, Faculty of Mechanical Engineering, Brno University of Technology; Technická 2896/2; 61669 Brno; CZ, dominika.fialova@vutbr.cz

** Assoc. Prof. Zdeněk Jegla, Ph.D.: Institute of Process Engineering, Faculty of Mechanical Engineering, Brno University of Technology; Technická 2896/2; 61669 Brno; CZ, jegla@fme.vutbr.cz
} 


\section{Specific industrial heat exchanger with multiple-level channel system}

Production of superheated steam is one of the most important and most frequent technological operations in process and power industries. Due to challenging technological requirements and generally low film heat transfer coefficient of flowing superheated steam, specific heat exchangers - so-called steam superheaters - used for this purpose have to be designed as tubular systems. The equipment is usually tailor-made to meet the required technological properties of the produced superheated steam (large flow rate, high temperature and pressure) in an effort to achieve maximum heat transfer rate. In the vast majority of cases, however, this approach leads to unique and complex tubular heat exchangers with a characteristic multiple-level channel system. Example of such an apparatus can be found in Figure 1.

Complex heat exchangers often suffer from heat and fluid flow maldistribution, which in particular badly affects the overall performance and (with respect to the used materials) service life of the equipment. Technological functions are negatively influenced by the hot stream (flue gas), which is not distributed uniformly in the shell side of the exchanger and across the tube bundle. In addition, non-uniformly distributed steam can also significantly increase an effect of flue gas maldistribution on heat transfer into the individual tubes. Described non-uniformities had a negative impact on a steam boiler and its most vulnerable part - the steam superheater discussed in this work (see Figure 1). Repeated superheater-tube failures caused several outages and repairs of the whole unit.

The mentioned steam superheater represents a single heat exchanger module placed in the second pass of the steam boiler. In Figure 1 it is shown together with a part of the membrane wall (surrounding the second pass of the flue gas channel) and with the vertical tube bundle supports. Construction-wise, the superheater contains a splitting manifold (distributor), combining manifold (collector), and the tube bundle. 102 tubes in three inline rows lead from the distributor and then, after approx. $500 \mathrm{~mm}$ from the membrane wall, are further split via "Y"-shaped segments. In total, the tube bundle consists of 198 tubes arranged in six passes.

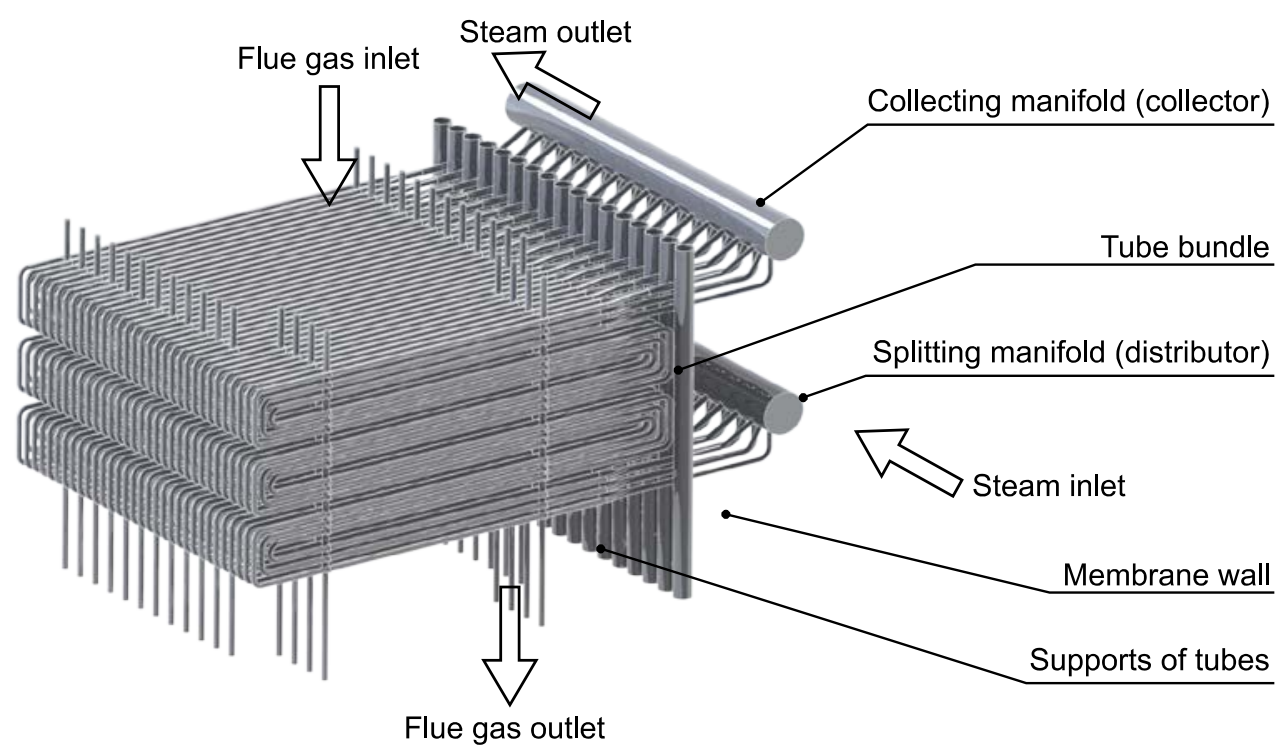

Fig. 1: Part of the tubular steam superheater discussed herein.

\section{Available models of heat and fluid flow distribution in multiple-level channel systems}

Suitable analytical models able to investigate flow distribution in tube bundles in very short time frames are usually based on the works presented by Bailey (1975), Bajura and Jones (1976), or Ngoma and Godard (2005). Bailey (1975), as well as Bajura and Jones (1976), utilised a branch-by-branch approach to solving the respective isothermal models. In case of such one-dimensional approach, the simplified models are usually tailor-made to specific equipment. However, the implemented correction factors (coefficient of static regain and discharge coefficient) make it possible to evaluate flow distribution even in flow systems with very complicated geometry (multiple tubes per loop, multiple-pass tube bundles, variable cross-section of the headers, etc.). Ngoma and Godard (2005) show a route to model nonuniform heat flux into the tubes and to monitor temperature profile in both manifolds. Though their 
approach is satisfactory to representing equipment with rather simple geometry, without additional artificial coefficients this model is not applicable to the steam superheater in question. Distribution of heat flux in the more complex tube bundle can also be modelled using 2D calculation methods such as the cell-method (Hewitt, 1998), which is well-established in the field of shell-and-tube heat exchangers. Alternatively, there is an option of a highly sophisticated approach to solving heat transfer, which employs a combination of CFD simulations and simplified analytical methods - as it is presented for example by Starace et al. (2017). Previous CFD studies presented e.g. by Carluccio et al. (2005) provide various correction coefficients as well as typical values for the respective parameters for a simplified cross-flow method, which is applied to each layer of the compact heat exchanger. As is apparent from the mentioned papers, finding the prediction functions needed for the purposes of hybrid methods is far from trivial and extremely time-consuming. The discussed steam superheater is - at least for now - too complex to be described by a similar model.

\section{Outline of the model and its future development}

The authors' aim is to develop a simplified calculation model which will enable engineers to predict flow behaviour of both process fluids (in terms of flow maldistribution) in the described type of steam superheater. Furthermore, it will provide accurate-enough information about non-uniformly distributed heat flux in the individual parts of the tube bundle.

A preliminary phase aims to yield the boundary conditions - flow rates and temperature of both fluids. In this stage, it is assumed that fluid in a distributor has a constant temperature. Therefore the new model predicts fluid flow distribution in a tube bundle by utilising a fast isothermal simulation based on (Bailey, 1975). His approach offers a big advantage over the analytical model introduced by Bajura and Jones (1976) since it employs simpler correction terms. Moreover, Bailey's model requires only a few modifications to describe the particular flow geometry. A study carried out by Nad' (2017) supplied the necessary information about temperature and velocity fields in the second pass of the boiler just above the steam superheater discussed herein. Hence, the flue gas distribution information is available and can be used as input data for a detailed modelling of flue gas flow in the shell side of the superheater.

Consequently, heat transfer should be evaluated using simplified 2D methods (the cell method or the cross-flow analysis). However, neither of these methods is able to analyse heat transfer in an equipment which is similar in appearance to the discussed heat exchanger. For example, the cell method does not distinguish individual tubes in every pass, not to mention that usage of the cross-flow calculation method is limited to single-pass exchangers. Overall, it is necessary to solve three problems arising from complicated design and construction of steam superheaters such as the one discussed herein: (i) determine the number of tubes per loop; (ii) analyse flue gas flow across the tube bundle (mixed fluid); and (iii) make provision for channel curvature. This implies that especially modifications of heat distribution analysis are inevitable in the further development of the new model. Future work will, therefore, focus on the development of a cross-flow method with an implementation of a cell-method technique - dividing the whole apparatus into a set of subexchangers (one per each tube pass).

The outline of the proposed modelling method is schematically illustrated in Figure 2. In terms of temperature, inlet boundary conditions yielded by above-mentioned approaches (for the cold and hot fluid, subscript 1 and 2, respectively) can be written as follows:

$$
\begin{gathered}
t_{1}{ }^{\text {inlet }}[x ; y]:=t_{1}[10 ; y=\{1 ; 2 ; 3\}]=\text { const., } \\
t_{2}^{\text {inlet }}[x ; y]:=t_{2}[x ; 6] .
\end{gathered}
$$

An iterative mechanism has to be used to obtain temperature fields across the tube bundle. Convergence criteria (3) and (4) on the tube and shell side, respectively, are checked until the absolute value of temperature difference in inlet regions reaches the required accuracy, $\varepsilon$.

$$
\begin{gathered}
\left|t_{1}^{\text {inlet }}-t_{1}[10 ; y=\{1 ; 2 ; 3\}]\right| \geq \varepsilon \\
\left|t_{2}{ }^{\text {inlet }}-t_{2}[x ; 6]\right| \geq \varepsilon
\end{gathered}
$$

Additionally, because mixing is not considered in the current 2D method for investigation into heat flux distribution, future activities will include tests of the influence of mixed/unmixed hot fluid on the accuracy of results and their comparison to experimental data from CFD analyses as well as the actual operating data. 


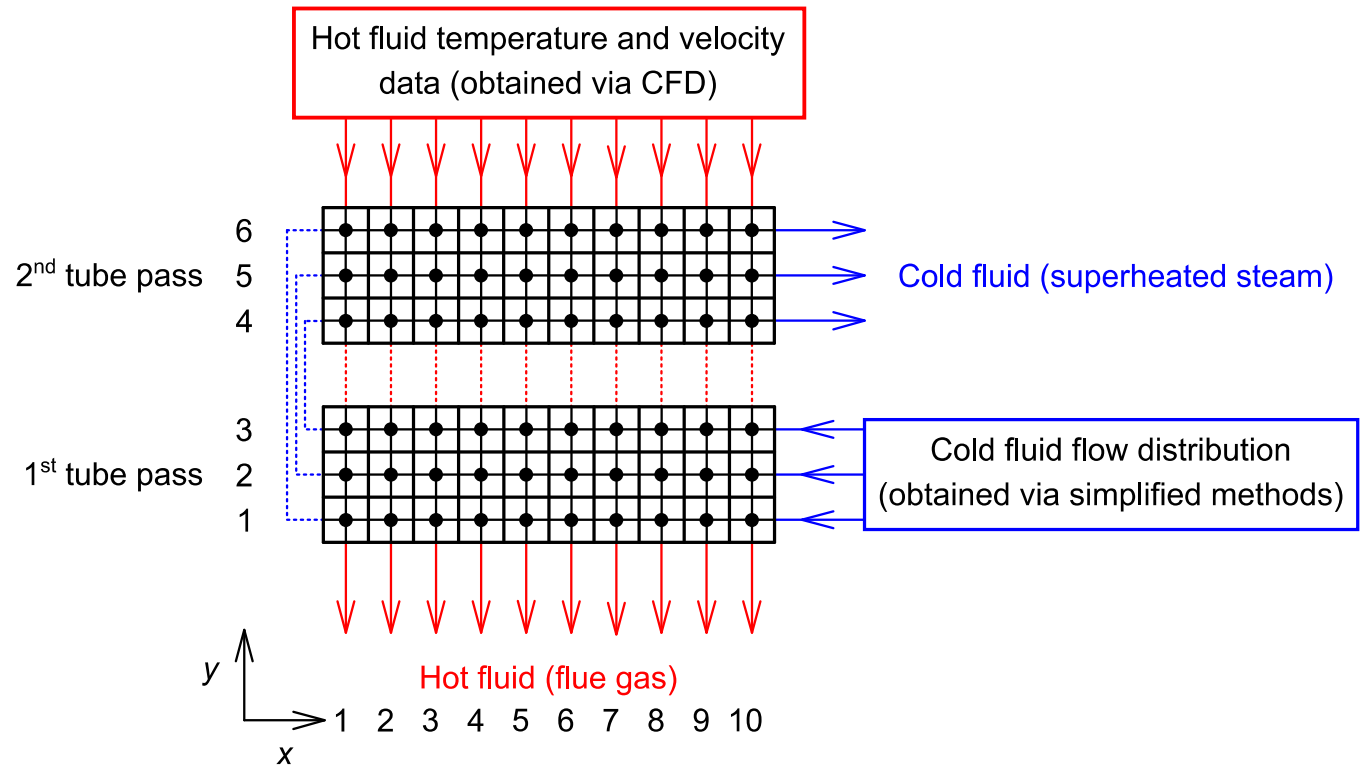

Fig. 2: Proposed modelling conception presented for a two-pass arrangement of the superheater.

\section{Conclusion}

This paper presents the initial conception of a calculation method for prediction of fluid flow and heat distribution in heat transfer equipment with multiple-channel designs commonly used in process and power industries. Through an example of a typical industrial steam superheater, the main theoretical findings are discussed. Based on the analysis of available calculation approaches, the model described by Bailey (1975) has been chosen to provide information about tube-side flow distribution, while the cross-flow subexchangers have been selected for 2D prediction of heat flux distribution. In such a way formulated model is able to predict a thermal-hydraulic behaviour of fluids which are inside the respective steam superheater. In order to achieve the overall objective - to obtain accurate-enough data quickly - the new model utilises a combination of CFD data and the above-mentioned simplified methods. So far, the proposed model has been tested on a constitutive two-pass arrangement of the steam superheater.

Apart from integration of fluid flow and heat distribution modelling methods, the resulting model will also need to be validated together with the underlying assumptions (e.g. the one regarding unmixed flow of hot fluid).

\section{Acknowledgement}

The authors gratefully acknowledge financial support within the project NETME CENTRE PLUS (LO1202) which was co-funded by the Ministry of Education, Youth and Sports within the support programme National Sustainability Programme I. The authors also sincerely thank for the financial support given by the Ministry of Education, Youth and Sports of Czech Republic under the standard specific research project FSI-S-17-4526.

\section{References}

Bailey, B. (1975) Fluid flow in perforated pipes. Journal of Mechanical Engineering Science, 17, 6, pp. 338-347.

Bajura, R. and Jones, E. (1976) Flow distribution manifolds. Journal of Fluids Engineering, 98, 4, pp. 654-666.

Carluccio, E., Starace, G., Ficarella, A. and Laforgia, D. (2005) Numerical analysis of a cross-flow compact heat exchanger for vehicle applications. Applied Thermal Engineering, 25, pp. 1995-2013.

Hewitt, G. (Ed.) (1998) Heat Exchanger Design Handbook, Begell House, Inc., New York.

Nad’, M., Jegla, Z., Létal, T., Lošák, P. and Buzík, J. (2017) Thermal load estimation for superheater tube bundle design. in: Machine Modeling and Simulations MMS 2017, Žilina, p. 30.

Ngoma, G. and Godard, F. (2005) Flow distribution in an eight level channel system, Applied Thermal Engineering 25, 5-6, pp. 831-849.

Starace, G., Fiorentino, M., Longo, M. P. and Carluccio, E. (2017) A hybrid method for the cross flow compact heat exchangers design. Applied Thermal Engineering 111, pp. 1129-1142. 